\title{
INDIVIDUAL SHAREHOLDERS' UNDERSTANDING OF THE CONTENT OF INTERIM REPORTS OF SOUTH AFRICAN Listed Retail CoMpanies
}

\author{
Johan GI Oberholster, Carolina Koornhof and Quintus Vorster \\ Department of Accounting, University of Pretoria \\ Accepted: October 2014
}

\begin{abstract}
A number of studies conducted, and reports published, by international and local accounting bodies have found that the proliferation of disclosures in financial reports has hampered users' understanding of these reports. The reports by accounting bodies also indicate that these users prefer more concise financial reports. These findings, in conjunction with a dearth of recent questionnaire-based research on whether individual shareholders understand the content of financial reports, resulted in this study on whether individual shareholders understand the content of interim reports. The study provides empirical proof that a sound knowledge of business, accounting and economic matters is a prerequisite for understanding interim reports in the case of individual shareholders. The results of the study indicate that individual shareholders have a limited understanding of the content of interim reports as a whole, and that a good knowledge of business and economic matters and of accounting results in an improved understanding of the content of interim reports. In particular, specialisation in accounting in undergraduate and postgraduate degrees, professional qualifications, and work experience in the financial field improve the understanding of individual shareholders.
\end{abstract}

Key words: individual shareholders, interim reports, qualitative characteristics, understanding, understandability

JEL: M410

\section{$1 \quad$ Introduction}

In South Africa, the accounting pronouncements of the International Accounting Standards Board (hereafter IASB) have been adopted as South African Accounting Standards since 1995 (Techtalk, 1995:4). These accounting pronouncements include the conceptual framework (the original conceptual framework and the original one currently being revised) of the IASB, International Accounting Standards, International Financial Reporting Standards (hereafter IFRS), as well as Interpretations of the IFRS Interpretations Committee (IASB, 2010).

The original conceptual framework was issued by the IASB in 1989 (IASC, 1989) and will hereafter be referred to as the 1989 IASB Framework, while the revised conceptual framework (IASB, 2010:Foreword) will hereafter be referred to as the 2010 IASB Framework.

Since the empirical work for this study was undertaken from 2008 to 2010, which spans a period when both the 1989 and 2010 IASB Frameworks were in force, both these conceptual frameworks were considered when dealing with theoretical concepts related to this study.

According to the 1989 IASB Framework, general-purpose financial reports (hereafter GPFRs) are financial reports that are prepared for a wide range of users and, as such, are designed to meet the common information needs of these users (IASC, 1989:§6). In the 2010 IASB Framework, it is stated that such reports are provided for shareholders, lenders and other creditors who cannot require entities to provide them with specific information directly (IASB, 2010:§OB5). In applying both these definitions of GPFRs, at least two types of financial reports could be identified as GPFRs. The first is a complete set of financial statements as described in IAS 1, Presentation of financial statements (IASB, 2012a: $§ 7$ ) and the second is an interim report (hereafter IR) as described in IAS 34, Interim financial reporting (IASB, 2012b). 
The qualitative characteristics identified in the 1989 and 2010 versions of the conceptual framework of the IASB have been described as characteristics that make financial information useful. According to the 1989 IASB Framework, "the four principal qualitative characteristics are understandability, relevance, reliability and comparability". In this conceptual framework, therefore, the four qualitative characteristics of financial information were considered to be of equal importance (IASC, 1989:\$24).

The 2010 IASB Framework identifies six qualitative characteristics of financial information and distinguishes between fundamental and enhancing qualitative characteristics. It states that, for financial information to be useful, "it must be relevant and faithfully present what it purports to present", and these two characteristics are considered to be fundamental in nature (IASB, 2010:\$QC5). The framework then elaborates on qualitative characteristics by claiming that "the usefulness of financial information is enhanced if it is comparable, verifiable, timely and understandable", and, as a result, the latter four characteristics are considered to be enhancing (IASB, 2010:§QC4).

To summarize the above in view of the focus of this article, understandability (or being understandable) is one of four principal qualitative characteristics in terms of the 1989 IASB Framework, while being understandable is considered to be an enhancing qualitative characteristic in terms of the 2010 IASB Framework. Clearly, understanding financial information is crucial to ensure that such information is useful to the users of financial statements. In this study, understanding is viewed as an indicator of understandability and the terms "understanding" and "understandability" are used interchangeably.

Several studies in recent years by leading accounting bodies in the world have indicated that the understanding of information contained in financial reports is compromised (ICAS \& NZICA, 2011:2; IFAC, 2008:28), and also that stakeholders would prefer to receive briefer financial reports (IASB, 2013:6; IFAC, 2011: 19; FRC, 2011:5, 6; ICAS \& NZICA, 2011:12; SEC, 2008:3; IFAC, 2008:353). Furthermore, the advent of integrated reporting and the use of IR formats in integrated reports have again highlighted the importance of IRs in South Africa (SAICA, 2012).

Consequently, this study focuses on whether the financial information contained in IRs published by South African listed retail companies is understood by the individual shareholders as users thereof. In addition, the study investigates whether individual shareholders with a reasonable knowledge of business and economic matters understand IRs better than those without such knowledge.

The constructs used in this study are now briefly explained:

IRs are financial reports presented for a financial-reporting period shorter than a full financial year and are issued to ensure that stakeholders are updated at intervals shorter than a 12-month period (IASB, 2012b:§4). "Individual shareholders" are defined as all shareholders, excluding companies or their equivalent, partnerships, joint shareholders, investment clubs, deceased estates, trusts, insurance companies, nominees, investment managers, medical aid funds, and pension, provident and other retirement funds for each company, as well as individual shareholders as defined that reside outside the borders of South Africa and Namibia. "Understanding" is discussed in detail as part of the literature review in Section 2.

\section{Literature review of the understanding of IRs}

From a literature review of the understandability and understanding of GPFRs, it appears as if no study on this topic has been published in South Africa, and neither has such a study been published in respect of IRs.

During the review of the literature on the understanding and understandability of financial information, it emerged that, in the majority of cases, readability and understandability (understanding) of annual and other reports were assessed using readability formulas and the Cloze procedure, and not questionnaires (Kumar, 2014:4; David, 2001:201; Smith \& Taffler, 1992:88-84). Readability formulas use word and sentence length to assess the ease with which narrative text can be read (Kumar, 2014:4; Courtis, 2004:297), while the Cloze procedure 
measures the level of interaction between readers of the material and the material itself, and, in doing so, measures the difficulty of reading as well as the level of comprehension of a narrative piece for a specific audience (Clatworthy \& Jones, 2001:312). In the case of both the techniques mentioned here, the focus is on the understanding of narrative information, while, in this study, the focus is on the understanding of the content of IRs as a whole and not only narrative information. In addition, owing to the abbreviated content of IRs, the narrative information contained in IRs is limited, and this complicates the application of the two techniques mentioned. According to Smith and Taffler (1992:88-84), readability formulas should not be used to assess understanding, since their research has shown that readability and understandability are different concepts. For these reasons, the questionnaire-based studies of Lee and Tweedie of 1975, 1976 and 1977 are used as the point of departure in developing a questionnaire to assess whether South African users of IRs understand the content of IRs (Lee \& Tweedie, 1975, 1976, 1977).

"Understandability" or "understanding" as a term does not appear to have been well defined in the 1989 and 2010 IASB Frameworks. Instead, rather broad descriptions of what the term entails are provided. For instance, the 1989 IASB Framework states that an "essential quality of the information provided in financial statements is that it is readily understandable by users" (IASC, 1989:§25). The more recent 2010 IASB Framework (IASB, 2010:§QC30), as part of its discussion on enhancing qualitative characteristics, states that "classifying, characterising and presenting information clearly and concisely make it understandable" (emphasis in the original). Since these two definitions relate to the understanding of financial information (i.e. GPFRs), the meaning of the word "understand" was investigated further.

According to the Reader's Digest great illustrated dictionary (Reader's Digest, 1984: 1794), to "understand" means, among other things, to "perceive and comprehend the nature and significance of" and to "grasp the meaning intended or expressed by another". If the term "understand" is related to the accounting environment, and specifically to whether the content of IRs is understood by users, it means that users of IRs (individual shareholders) should perceive and comprehend the nature and significance of information contained in IRs, and also grasp the meaning intended or expressed by the preparers of the IRs - specifically, the content of IRs as in this study. Individual shareholders should thus understand the content of IRs. The interpretation in this study when relating the dictionary definition of understanding to accounting information is in line with the discussion by Eccles and Holt (2005:383) of the interpretation of understandability offered by the Accounting Standards Board (ASB) of the United Kingdom (hereafter UK). They indicate that understandability/understanding "requires that users are able to perceive the significance of information provided".

The explanations surrounding understandability in both the 1989 and 2010 IASB Frameworks were provided earlier in this section. Both these frameworks indicate that users should be able to understand the information presented in GPFRs. However, both these conceptual frameworks introduce a caveat in respect of the knowledge base of the assumed users.

The 1989 IASB Framework indicates that, to understand GPFRs, users are assumed "to have a reasonable knowledge of business and economic activities and accounting and a willingness to study the information with reasonable diligence" (IASC, 1989:\$25). In the 2010 IASB Framework, the caveat in respect of who the users of GPFRs are is introduced once again by stating that the reports "are prepared for users who have a reasonable knowledge of business and economic activities and who review and analyse the information diligently" (IASB, 2010:§QC32). It is not clear why the reference to "accounting" was removed in the 2010 IASB Framework.

To summarise, "understanding" in the context of this study implies that individual shareholders must comprehend and perceive the significance of information contained in GPFRs (IRs in this specific instance). Assessing whether users understand the content of IRs, as is done in this study, will provide an indication of whether the content presented in IRs is understandable. To ensure that the understanding of individual shareholders was not adversely affected by the nature of the business of the company in which they invested, the study was limited to well-known listed retail companies whose business activities were clearly understood by the general public. 


\section{Research problem}

This article addresses the understanding of IRs of companies listed in the Retail Sector of the Johannesburg Stock Exchange (hereafter JSE) in South Africa, namely:

- whether individual shareholders understand the content of the IRs of these companies as a whole; and

- whether the caveat introduced by the IASB (i.e. in order for individual shareholders to understand IRs, such shareholders must have a reasonable knowledge of business and economic activities) is necessary in understanding IRs.

The study focuses on the understanding of IRs presented by retail companies listed on the JSE and does not address the usefulness of IRs for investment decisions per se. However, it stands to reason that, if shareholders do not understand the content of IRs, the usefulness of IRs will be compromised.

\section{Research method}

\subsection{Postal questionnaire}

In Section 2, the reason why a decision was taken to use a questionnaire-based research approach to assess the understanding of the content of IRs, was explained. Also, in that section, the fact that the questionnaires used by Lee and Tweedie in their studies of the understanding of annual reports by individual shareholders were used as the point of departure in this study, was alluded to.

Although Lee and Tweedie, in their main questionnaire-based UK study of 1977, used an interview-based approach (Lee \& Tweedie, 1977:12), a postal-questionnaire approach, similar to that of Bartlett and Chandler in their 1997 UK postal-questionnaire survey on annual reports, was used in this study. This choice of research method can be justified in view of the fact that the results of the interview-based UK studies of Lee and Tweedie did not appear to differ significantly from those of their postal-questionnaire studies (Bartlett \& Chandler, 1997:250). Bartlett and Chandler also used the questions of Lee and Tweedie in respect of annual financial reports as the point of departure when developing their questionnaire, but adapted these in line with developments in financial accounting in the UK from 1975 to 1995 (Bartlett \& Chandler, 1997:249). In this South African study, the questionnaires of Lee and Tweedie are adjusted to a greater extent, as IRs were used rather than annual reports, and because accounting developments over more than 30 years since the Tweedie and Lee studies were completed, had to be accommodated.

Questions on demographic information were included to assess whether users of IRs with a business, economic and accounting background and experience in business, economics and accounting had a better understanding than those without such background or experience.

The Lee and Tweedie study on the understanding of individual shareholders of annual financial reports in 1977 was divided into five main areas: the financial-reporting environment, the main valuation bases used in accounting in respect of particular assets, the content of financial statements, commonly used accounting terminology, and financial ratios (Lee \& Tweedie, 1977:28, 29).

For this South African study, only three of the five areas identified by Lee and Tweedie were used. Basic questions on the main valuation bases used in accounting with regard to particular assets, the content of financial statements, and commonly used accounting terminology were included in the questionnaire. These areas were collectively described as the content of IRs in this study. The area related to the financial-reporting environment was eliminated, since these questions are related to the context of the issuance of IRs and not to the content of IRs. Similarly, the area related to financial ratios contained in the Lee and Tweedie study was excluded, as IRs do not always include financial ratios because these are not prescribed from a regulatory perspective. 


\subsection{Companies and IIRs used as part of the survey}

In the 1977 study of Lee and Tweedie on the understanding of annual reports, the individual shareholders of one of the largest listed companies in the UK were targeted and were then limited to four geographical locations to facilitate the conducting of interviews (Lee \& Tweedie, 1977:13).

In this study on IRs, the study targeted the individual shareholders of three listed retail companies from the Retail Sector of the JSE. The IRs used to assess the understanding of individual shareholders related to interim periods ending on 31 December 2008, 28 February 2009 and 31 December 2010. The interim periods listed are those of the three large retail companies that were prepared to permit the research instrument (questionnaire) to accompany the related IRs when these were distributed to their individual shareholders. The list of amendments to IAS 34 since 2007 indicated that no changes to the standard that would have an impact on the research questionnaire had been made up to this point in time (IASB, 2013:Amendments). It is thus submitted that the outcome of the research would have been no different if IRs issued at a later date had been used in this survey. Retail companies were selected, since it was believed that individual shareholders of such companies would have a clearer understanding of the business of such companies, as the activities of the majority of listed retail companies are well known to the public at large. By contrast, individual shareholders may find it difficult to understand the business of companies involved in, for instance, the banking, mining or computer technology sectors. The market capitalisation of the three listed retail companies represented approximately 30 per cent of the market capitalisation of companies in that sector.

\subsection{Selection of sample and response rate}

The postal questionnaires were sent to the individual shareholders of the three different companies mentioned in Section 4.2. The names of the companies that were willing to participate in the survey were not known at the beginning of the study, and, consequently, the systematic randomsampling technique was used to select the individual shareholders who would form part of the sample. Every second individual shareholder of each company was selected for the survey, and the starting point for systematic sampling in the case of each company was determined by tossing a coin.

Out of a population of 12976 individual shareholders of the three companies, a total of 6488 questionnaires (50 per cent) were mailed to the same individual shareholders during two mailing events scheduled six weeks apart. In the first mailing event, the original, relevant IR sent to shareholders accompanied the questionnaire, and, during the second one, a copy of the relevant IR was sent to such shareholders. To improve the response rate of the survey, the survey was kept anonymous.

A total of 1102 respondents (individual shareholders) replied after the two mailing events, and this represented a response rate of 17.48 per cent.

\subsection{Evidence of understanding of the content of IRs}

To assess whether individual shareholders (respondents) understood the content of the IRs, marks were awarded to each individual question on the content of IRs. These questions added up to 18 possible marks and the marks were allocated to individual questions on the following basis:

- One mark was awarded where the answer to a question was evident from information in the IR or from the various options provided as part of the question.

- Two marks were awarded to questions where the answer to the question was not evident from the IR and required a broader knowledge of accounting matters.

- Three marks were awarded in one instance, i.e. where individual shareholders needed detailed accounting knowledge to answer the question.

The questions answered in the questionnaires returned by individual shareholders were scored for each respondent. The score out of 18 is expressed as a percentage and is referred to as the total percentage score of each respondent in this study. A percentage of 50 was deemed to reflect an acceptable benchmark of understanding. 


\subsection{Non-response bias}

To ensure that respondents were representative of the sample as a whole, the existence of non-response bias was investigated through extrapolation (early versus late respondents and firstand second-wave analysis) (Armstrong \& Overton, 1977:397; Wagner \& Kemmerling, 2010:368).

The t-test statistic determined when comparing the means of the total percentage scores of the first and second waves indicated that there was no statistically significant difference between the means for the first (early respondents) and second (late respondents) waves. This is because the null hypothesis could not be rejected at the 5 per cent level in either of the two instances $(\mathrm{p}=0.3163)$.

The assessment thus provided no evidence of non-response bias.

\section{Research results}

Although 1102 respondents completed the questionnaire, not all respondents answered every question in the questionnaire, and thus the number of respondents that appears in tables presented in this section may vary. The number of respondents is provided as $n$ in each table presented.

\subsection{Assessing understanding by individual shareholders of the content of IRs as a whole}

To address the first research objective of the study, namely whether individual shareholders understand the content of IRs as a whole, the questionnaire discussed earlier contained a number of questions and statements designed to assess the understanding of the content of IRs by respondents. The following are examples of such questions and statements:

- What basis of valuation was used to determine the carrying amounts of property, plant and equipment, and inventories contained in the Condensed Statement of Financial Position?

- The line-item for tax in the Condensed Statement of Comprehensive Income includes merely the tax payable to SARS [South African Revenue Service]. Select "Yes", "No" or "I don't know".

- The final balances on the Condensed Statement of Changes in Equity can be linked to the Condensed Statement of Financial Position. Select "Yes", "No" or "I don't know".

- The purchase of property, plant and equipment on credit would represent a cash outflow in the Condensed Statement of Cash Flows. Select "Yes", "No" or "I don't know".

The total percentage scores achieved by individual shareholders indicate their understanding of IRs assessed using the research instrument (questionnaire), and the frequency distribution table below was constructed to facilitate a descriptive analysis of the data. The number of responses in the case of each variable was used as a point of departure to calculate the relative value or percentage of responses in that specific instance. Table 1 below provides an overview of the results collected in respect of the first research objective.

Table 1

Frequency table and mean of total percentage score achieved by individual shareholders in the assessment of their understanding of the content of IRs as a whole

\begin{tabular}{|l|c|c|c|c|}
\hline $\begin{array}{c}\text { Total percentage score achieved by } \\
\text { respondents (score out of 18 in brackets } \\
\text { and } \mathbf{n = 1} \text { 102) }\end{array}$ & Frequency & Percentage & $\begin{array}{c}\text { Cumulative } \\
\text { frequency }\end{array}$ & $\begin{array}{c}\text { Cumulative } \\
\text { percentage }\end{array}$ \\
\hline $100.00(18)$ & 2 & 0.18 & 2 & 0.18 \\
\hline $94.44(17)$ & 19 & 1.72 & 21 & 1.90 \\
\hline $88.89(16)$ & 10 & 0.91 & 31 & 2.81 \\
\hline $83.33(15)$ & 63 & 5.72 & 94 & 8.53 \\
\hline $77.78(14)$ & 18 & 1.63 & 112 & 10.16 \\
\hline $72.22(13)$ & 78 & 7.08 & 190 & 17.24 \\
\hline $66.67(12)$ & 44 & 3.99 & 234 & 21.23 \\
\hline
\end{tabular}




\begin{tabular}{|c|c|c|c|c|}
\hline $\begin{array}{l}\text { Total percentage score achieved by } \\
\text { respondents (score out of } 18 \text { in brackets } \\
\text { and } n=1102 \text { ) }\end{array}$ & Frequency & Percentage & $\begin{array}{l}\text { Cumulative } \\
\text { frequency }\end{array}$ & $\begin{array}{l}\text { Cumulative } \\
\text { percentage }\end{array}$ \\
\hline $61.11(11)$ & 57 & 5.17 & 291 & 26.40 \\
\hline $55.56(10)$ & 101 & 9.17 & 392 & 35.57 \\
\hline 50.00 (9) & 42 & 3.81 & 434 & 39.38 \\
\hline $44.44(8)$ & 91 & 8.26 & 525 & 47.64 \\
\hline $38.89(7)$ & 47 & 4.27 & 572 & 51.91 \\
\hline $33.33(6)$ & 85 & 7.71 & 657 & 59.62 \\
\hline $27.78(5)$ & 54 & 4.90 & 711 & 64.52 \\
\hline $22.22(4)$ & 61 & 5.54 & 772 & 70.06 \\
\hline $16.67(3)$ & 35 & 3.18 & 807 & 73.24 \\
\hline $11.11(2)$ & 97 & 8.80 & 904 & 82.04 \\
\hline $5.56(1)$ & 17 & 1.54 & 921 & 83.58 \\
\hline $0.00(0)$ & 181 & 16.42 & 1102 & 100.00 \\
\hline
\end{tabular}

From Table 1, it is clear that 39.38 per cent of respondents achieved a total percentage score of 50 or more, or that 35.57 per cent of respondents achieved a total percentage score of above 50 . Of the total respondents, 60.62 per cent achieved a score below 50 per cent, and just more than 52.36 per cent of respondents achieved about 39 per cent or below. The mean of total percentage score achieved by respondents in respect of the content of the IRs was 38.67 per cent, which is substantially below the benchmark of 50 per cent identified in Section 4.4 of this study.

It can thus be concluded that, in respect of the first research objective of the study, the majority of respondents in the survey displayed a limited understanding of the content of IRs as a whole.

\subsection{The understanding of the content of IRs as a whole is related to the level of knowledge of business and economic activities}

In Section 5.1, it was concluded that individual shareholders do not have a good understanding of the content of IRs as a whole. The understanding of IRs by individual shareholders was further analysed for demographic variables that should contribute to individual shareholders having a better knowledge of business, economics and accounting, etc. These demographic variables contained in the demographics section of the questionnaire relate to education and occupation and include:

- whether respondents hold a degree or not;

- the area of specialisation of the degree held by respondents;

- whether respondents hold postgraduate degrees or the equivalent;

- whether respondents hold a professional qualification; and

- the field of work experience of respondents.

The association between education (degree or no degree, area of specialisation of degree, and whether postgraduate degrees or the equivalent are held) and occupation (professional qualification and field of work experience) on the one hand and the understanding of the content of IRs on the other, was analysed.

\subsubsection{Holding a degree or not and understanding of the content of IRs as a whole as indicated by average total percentage score}

Table 2

T-test between respondents with a degree or no degree and understanding of the content of IRs $(n=1102)$

\begin{tabular}{|c|c|c|c|}
\hline \multicolumn{2}{|c|}{ Degree $(\mathbf{n = 6 3 2})$} & \multicolumn{2}{c|}{ No degree $(\mathbf{n = 4 7 0 )}$} \\
\hline $\begin{array}{c}\text { Mean (average total } \\
\text { percentage score) }\end{array}$ & Standard deviation & $\begin{array}{c}\text { Mean (average total } \\
\text { percentage score) }\end{array}$ & Standard deviation \\
\hline 44.7609 & 28.9039 & 30.4728 & 23.7878 \\
\hline$T=-9.06, p<0.0001$ & & & \\
\hline
\end{tabular}


A t-test for two independent samples was performed to assess whether the means of the total percentage score of respondents with a degree and respondents without a degree differed. A t-test compares the means for the same variable between two groups and enables a researcher to assess the magnitude of the difference between the means calculated for these groups, relative to the spread or variability of their scores.

For the above-mentioned test, the assumption of equal variances was violated, and, consequently, the Satterthwaite method was used $(\mathrm{T}=-9.06, \mathrm{DF}=1092.3)$, indicating that the null hypothesis should be rejected at the 5 per cent level $(\mathrm{p}<0.0001)$. This relates to a medium effect size $(\mathrm{r}=0.26)$ and Pearson's correlation coefficient $r$ was used as the measure of effect size. The interpretation thereof is based on the widely accepted norms associated with effect size (Field, 2005:32).

The outcome of this test was that the mean in respect of understanding of the content of the IR as a whole indicated that the understanding of respondents holding a degree (mean $=$ 44.76) and of those respondents not holding a degree (mean $=30.47)$ differed significantly.

The total percentage scores indicating understanding of the content of IRs as a whole for both respondents with a degree and without a degree were disappointingly low, but respondents with a degree had a better understanding of the content of IRs as a whole than those not holding a degree.

\subsubsection{Area of specialisation of degree and understanding of the content of IRs as a whole}

\section{Table 3}

ANOVA with specialisation area of degree as independent variable and average total percentage score on content as dependent variable $(n=632)$

\begin{tabular}{|l|l|c|c|}
\hline \multicolumn{1}{|c|}{ Test result } & \multicolumn{1}{|c|}{ Breakdown of demographic group } & $\begin{array}{c}\text { Means (average total } \\
\text { percentage score) }\end{array}$ & $\begin{array}{c}\text { Standard } \\
\text { deviation }\end{array}$ \\
\hline F = 99.09, DF1 $=5$, & - BSc non-medical $(n=69)$ & $29.7907^{\text {ad }}$ & 21.2186 \\
DF2 = 229.5 and & - BCom, not Accounting $(n=91)$ & $47.9243^{\text {b }}$ & 24.2818 \\
p<0.0001 (Welch) & - BCom Accounting $(n=147)$ & $74.1119^{\mathrm{c}}$ & 17.0367 \\
& - Engineering + related $(n=82)$ & $42.8184^{\text {bc }}$ & 23.7713 \\
& - Medicine + related $(n=59)$ & $27.5895^{\text {a }}$ & 24.6294 \\
& - BA/Theology/Law, etc. $(n=184)$ & $31.7331^{\text {d }}$ & 26.4680 \\
\hline \multicolumn{2}{|l|}{ Means identified by different superscripts differ significantly at the 5\% level. } \\
\hline
\end{tabular}

An ANOVA was performed to determine whether the understanding of the content of the IR as a whole was the same for respondents grouped by area of specialisation of the undergraduate degree. An analysis of variance (ANOVA) was used here, since statistical differences for more than two groups were assessed to determine whether the means (average number) were the same.

According to Levene's test, the assumption of equal variance was violated $(p<0.0001)$ and thus Welch's test statistic was used. The null hypothesis that there are no differences between the means of total percentage scores of different degree-specialisation groups was rejected $(\mathrm{F}=99.09$, $\mathrm{DF} 1=5, \mathrm{DF} 2=229.5, \mathrm{p}<0.0001)$. This relates to a strong effect size $(\mathrm{r}=0.60)$. There are statistically significant differences between the average total percentage scores (means) of respondents with degrees with differing areas of specialisation. This is confirmed by the means or average total percentage scores (see Table 3 above), which show BCom (Accounting) graduates $($ mean $=74.11)$ and other BCom graduates $($ mean $=47.92)$ to have the highest means. Respondents with degrees in medicine and related focal areas appear to have the lowest mean (27.59). Post hoc tests confirmed that the mean of respondents holding BSc non-medical degrees $($ mean $=29.79)$ differs significantly from the means of the three groups of respondents who held non-accounting BCom degrees (mean $=47.92)$, BCom (Accounting) degrees (mean $=74.11)$ and engineering-related degrees (mean $=42.82$ ). However, the mean of BSc non-medical degrees does not differ significantly from that of respondents who held degrees in medical fields $($ mean $=27.59)$ and sundry other degrees $($ mean $=31.73)$.

Respondents holding BCom (Accounting) degrees have the highest mean of total percentage scores, indicating that knowledge of business, accounting and economic matters improves understanding of the content of IRs as a whole. 


\subsubsection{Postgraduate degrees and understanding of the content of IRs as a whole}

Table 4

ANOVA with postgraduate degree status as independent variable and average total percentage score on content as dependent variable $(n=1$ 102)

\begin{tabular}{|l|l|c|c|}
\hline \multicolumn{1}{|c|}{ Test result } & Breakdown of demographic group & $\begin{array}{c}\text { Means (average total } \\
\text { percentage score) }\end{array}$ & $\begin{array}{c}\text { Standard } \\
\text { deviation }\end{array}$ \\
\hline$F=60.28$, DF1 $=2$, & - No PG qualification $(n=764)$ & $33.0061^{\text {a }}$ & 24.7051 \\
DF2 $=284.1$ and $p<0.0001$ & - Honours or equivalent ${ }^{1}(n=189)$ & $57.4662^{\mathrm{b}}$ & 29.2703 \\
(Welch) & - Master's \& PhD $(n=149)$ & $43.8479^{\mathrm{c}}$ & 28.0552 \\
\hline \multicolumn{2}{|l|}{ Means identified by different superscripts differ significantly at the 5\% level. } \\
\hline
\end{tabular}

An ANOVA was performed to determine whether the understanding of IRs was the same, irrespective of whether respondents held postgraduate degrees or of the level of their postgraduate degrees.

According to Levene's test, the assumption of equal variance was violated $(p<0.0001)$ and thus Welch's test statistic was used. The null hypothesis that there are no differences between the average total percentage scores of respondents holding no or different levels of postgraduate degrees should be rejected $(F=60.28$, DF1 $=2$, DF2 $=284.1, p<0.0001)$. This relates to a medium effect size $(r=0.34)$. It can thus be concluded that there are statistically significant differences between the average total percentage scores (means) of respondents holding no or different levels of postgraduate degrees. This is confirmed by the fact that the average total percentage scores of graduates holding honours degrees or equivalents (mean $=57.47$ ) were higher than those of both respondents who do not hold a higher degree (mean $=33.01)$ and those holding master's degrees and PhDs (mean $=43.85)$. Post hoc tests confirm that the means associated with respondents from all three groups differ significantly from one another.

Respondents who do not hold a post-graduate degree achieved the lowest average total percentage score $($ mean $=33.01)$. Respondents holding an honours degree or an equivalent as their highest postgraduate qualification appeared to understand the content of IRs as a whole, with a mean of approximately 58 per cent. This can probably be attributed to the fact that 103 (56 per cent) of these respondents specialised in Accounting Sciences in their honours degree or postgraduate diploma (equivalent). Although no conclusion regarding this phenomenon could be drawn from the data, it is possible that respondents with a business degree are keener to invest in listed retail companies or that they tend to invest on their own initiative rather than through advisers, unit trusts or index funds.

The mean of the group of respondents holding master's degrees and $\mathrm{PhDs}$ in a diverse range of fields was approximately 44 per cent. The apparent anomaly that respondents with honours degrees or the equivalent have a better understanding of IRs than respondents with master's and $\mathrm{PhD}$ degrees may also be linked to the fact that respondents who have an honours degree or Postgraduate Diploma in Accounting Sciences as their highest qualification in South Africa have probably qualified as chartered accountants.

\subsubsection{Professional qualification held and understanding of the content of IRs as a whole}

Table 5

ANOVA with professional qualification held as independent variable and average total percentage score on content as dependent variable $(n=520)$

\begin{tabular}{|l|l|c|c|}
\hline \multicolumn{1}{|c|}{ Test result } & Breakdown of demographic group & $\begin{array}{c}\text { Means (average } \\
\text { total percentage score) }\end{array}$ & $\begin{array}{c}\text { Standard } \\
\text { deviation }\end{array}$ \\
\hline $\mathrm{F}=95.44, \mathrm{DF} 1=4, \mathrm{DF} 2=515$ & - Teaching $(\mathrm{n}=77)$ & $21.6450^{\mathrm{a}}$ & 22.1597 \\
and $\mathrm{p}<0.0001$ & - Engineering \& related $(\mathrm{n}=118)$ & $38.4181^{\mathrm{b}}$ & 24.5092 \\
& - Medical field $(\mathrm{n}=86)$ & $25.7752^{\mathrm{a}}$ & 23.2899 \\
& - Financial $(\mathrm{n}=190)$ & $67.6316^{\mathrm{c}}$ & 21.2734 \\
& - Legal \& other $(\mathrm{n}=49)$ & $24.3764^{\mathrm{a}}$ & 22.5045 \\
\hline \multicolumn{2}{|l}{} \\
\hline
\end{tabular}


An ANOVA was performed to determine whether the understanding of the content of the IR as a whole was the same for respondents split into groups based on professional qualification.

According to Levene's test, the assumption of equal variances was not violated $(p=0.3978)$. The null hypothesis that there is no difference among the means of total percentage score of different professional qualification groups should be rejected $(\mathrm{F}=95.44, \mathrm{DF} 1=4, \mathrm{DF} 2=515$, $\mathrm{p}<0.0001)$. This relates to a large effect size $(\mathrm{r}=0.65)$. It can therefore be concluded that there are statistically significant differences between the average total percentage scores based on the professional qualification of respondents. This was confirmed by the means, which show that respondents with a finance-related professional qualification (mean $=67.63$ ) outperformed those with professional qualifications in the teaching, medical, legal and other fields (means range between 21.65 and 25.78). Post hoc tests confirmed that the mean of the average total percentage score of respondents from the teaching profession $($ mean $=21.65)$ differs significantly from that of all professional groupings, except for respondents in the medical profession (mean $=25.78)$ and legal and other professions (mean $=24.38$ ).

The mean of total percentage scores of the finance-related professions is more than double that of the teaching, medical, and legal and other professions. This appears to confirm that members of the finance-related professions may have more exposure to accounting, finance and investments and should thus have a better understanding of the content of IRs as a whole.

\subsubsection{Field of work experience and understanding of the content of IRs as a whole}

\section{Table 6}

ANOVA with field of work experience as independent variable and average total percentage score on content as dependent variable $(n=1085)$

\begin{tabular}{|l|l|c|c|}
\hline \multicolumn{1}{|c|}{ Test statistic } & \multicolumn{1}{|c|}{$\begin{array}{c}\text { Breakdown of demographic } \\
\text { groups }\end{array}$} & $\begin{array}{c}\text { Means (average total } \\
\text { percentage score) }\end{array}$ & $\begin{array}{c}\text { Standard } \\
\text { deviation }\end{array}$ \\
\hline $\mathrm{F}=83.37, \mathrm{DF} 1=3, \mathrm{DF} 2=$ & - Acc/Invest/Bank/Fin $(\mathrm{n}=324)$ & $56.6015^{\mathrm{a}}$ & 26.0460 \\
1081, and $\mathrm{p}<0.0001$ & - Medical/Legal $(\mathrm{n}=122)$ & $26.2750^{\mathrm{b}}$ & 24.6808 \\
& - Engineering, related $(\mathrm{n}=190)$ & $37.0458^{\mathrm{c}}$ & 23.9145 \\
& - Other $(\mathrm{n}=449)$ & $30.3514^{\mathrm{b}}$ & 24.3914 \\
\hline \multicolumn{2}{|l|}{ Means identified by different superscripts differ significantly at the 5\% level. } \\
\hline
\end{tabular}

An ANOVA was performed to determine whether the understanding of the content of the IR as a whole was the same for all groups of respondents irrespective of work experience.

The null hypothesis that there is no difference between the average total percentage scores of different groups based on field of work experience should be rejected $(\mathrm{F}=83.37$, DF1 $=3$, DF2 = $1081, \mathrm{p}<0.0001)$. This relates to a large effect size $(\mathrm{r}=0.43)$. It can therefore be concluded that there is convincing evidence of statistically significant differences between the means based on the fields of work experience of respondents. Respondents with experience in accounting, investing, banking and finance $($ mean $=56.60)$ performed better than those who have work experience in "other" fields (mean $=30.35)$. Post hoc tests indicate that the mean of the total percentage scores of respondents with experience in the accounting, banking, financial and investment fields differs significantly from the means of the total percentage scores of the medical/legal fields (mean $=26.28)$, engineering/construction and related fields (mean $=37.05)$, and other fields of work experience. The lower mean for the accounting/investing/banking and finance group (56.60 per cent) compared with respondents with Accounting as the area of specialisation in their undergraduate degrees (74.11 per cent - see Table 3) can be attributed to the fact that "field of work experience" is not focused on accounting exclusively (it includes a diverse group of qualifications such as engineering degrees and Masters in Business Administration), whereas, in the other instance, Accounting is the field of specialisation.

Respondents with work experience in the fields of accounting, investment, banking and finance have a higher mean of total average percentage score than those with work experience in other fields. 


\section{Conclusion and future research}

\subsection{Conclusion}

This study was conceived in order to draw conclusions regarding two matters relating to JSE-listed retail companies, namely:

- whether individual shareholders understand the content of IRs as a whole; and

- whether the caveat of the IASB (i.e. in order for individual shareholders to understand IRs, they must have a reasonable knowledge of business and economic activities) holds true.

In the case of the first research objective, the finding of the study is that, overall, individual shareholders of JSE-listed retail companies appear to have a limited understanding of the content of IRs as a whole. This is borne out by the fact that the respondents, on average, achieved a mean of total percentage score of 38.67 per cent as opposed to an assumed acceptable total percentage score of 50, as explained in Section 4.4. A corresponding study on the level of understanding of individual shareholders in the case of a complete set of financial statements has not been conducted in South Africa. However, given the level of understanding of an abbreviated set of financial statements such as IRs, it would be surprising if the level of understanding in the case of a complete set of financial statements was to be higher than that in respect of IRs. The complexity of a complete set of financial statements would in all probability lead to a reduced level of understanding of the content thereof by individual shareholders.

In the case of the second research objective, it was found that respondents holding a degree have a better understanding of the content of IRs than those not holding a degree. In addition, the area of specialisation in the degree appears to have an impact on the understanding of the content of IRs, and respondents holding a BCom or BCom (Accounting) degree or equivalent have a better understanding of IRs as a whole than respondents holding degrees with other areas of specialisation.

Respondents holding honours degrees or the equivalent as the highest qualification have a better understanding of the content of IRs as a whole than respondents holding master's and doctoral degrees. This appears to be the case because the majority of these respondents hold honours degrees or a Postgraduate Diploma in Accounting (an equivalent).

Respondents with finance-related professional qualifications appear to have a better understanding of the content of IRs as a whole than respondents with professional qualifications unrelated to finance. Similarly, respondents with work experience in finance-related fields have a better understanding of the content of IRs as a whole than respondents not working in financerelated fields.

It should be borne in mind that a fairly large proportion of respondents in the case of this study had education, qualifications, or experience related to finance and that this may have increased the overall level of understanding of individual shareholders, as established in Table 1. It is not clear whether the higher proportion of respondents with education, qualifications, or experience of business and finance in the sample is linked to the profile of individual shareholders that invest in retail companies or whether such shareholders were more inclined to respond to the research instrument used in the study. This is the case despite non-response bias not being present in the sample.

Based on the above observations, it can be concluded that knowledge of business and economic matters and of accounting, whether acquired through education or work experience, appears to improve the understanding of the content of IRs as a whole of individual shareholders of JSElisted retail companies. The caveat introduced by the IASB that "financial reports are prepared for users who have a reasonable knowledge of business and economic activities" (IASB, 2010:§QC32) is thus empirically confirmed in the case of IRs and individual shareholders of listed retail companies in South Africa.

The limited understanding of individual shareholders of the content of IRs as a whole, as indicated in this study, as well as the possibility that the more complex, complete sets of financial 
statements would be understood to an even lesser extent, leads the researchers to propose that the IASB should state clearly under the objectives of GPFRs that users must have a reasonable knowledge of business and economic matters and of accounting in order to understand these financial reports. At this stage, this caveat is introduced only in paragraph QC 32 of the 2010 conceptual framework, where the enhancing qualitative characteristic of understandability is addressed, and no mention is made of accounting as such, while this study has indicated that it is an important factor contributing to the understanding of IRs.

Another proposal would be a requirement that all IRs presented by companies should clearly state that IRs are meant to be used only by users with a reasonable knowledge of business and economic matters and of accounting. If users do not have a reasonable knowledge of such matters, they should rather make use of financial advisers or use other investment vehicles, for example unit trust funds, pension funds and retirement annuities.

\subsection{Future research}

Given that the conclusions in this article relate to South African listed retail companies only, and that the individual shareholders of only three companies were used, a replication of the study for companies from other sectors of the JSE would be possible. In addition, further research could be conducted to establish how the understanding of IRs by individual shareholders could be improved in future, and whether or not the level of understanding of IRs by individual shareholders has an impact on their willingness to make their own investment decisions.

Endnote

1 "Equivalent" refers to postgraduate diplomas.

\section{References}

ARMSTRONG, J.S. \& OVERTON, T.S. 1977. Estimating nonresponse bias in mail surveys. Journal of Marketing Research, 14:396-402.

BARTLETT, S.A \& CHANDLER, R.A. 1997. The corporate report and the private shareholder: Lee \& Tweedie twenty years on. British Accounting Review, 29:245-261.

CLATWORTHY, M. \& JONES, M.J. 2001. The effect of thematic structure on the variability of annual report readabililty. Accounting, Auditing and Accountability Journal, 14(3):311-326.

COURTIS, J.K. 2004. Corporate report obfuscation: Artefact or phenomenon? British Accounting, Review, 36(3):291-312.

DAVID, C. 2001. Mythmaking in annual reports. Journal of Business and Technical Communication, April:195-222.

ECCLES, T. \& HOLT, A. 2005. Practice paper: Financial statements and corporate accounts: The conceptual framework. Property Management, 23(5):374-387.

FIELD, A. 2005. Discovering statistics using SPSS. London: Sage.

FRC (FINANCIAL REPORTING COUNCIL). 2011. Cutting clutter: Combatting clutter in annual reports. London: ASB.

IASB (INTERNATIONAL ACCOUNTING STANDARDS BOARD). 2010. Conceptual framework for financial reporting. September. London: IASB.

IASB (INTERNATIONAL ACCOUNTING STANDARDS BOARD). 2012a. Presentation of financial statements - IAS 1. London: IASB.

IASB (INTERNATIONAL ACCOUNTING STANDARDS BOARD). 2012b. Interim financial reporting IAS 34 (revised version). London: IASB.

IASB (INTERNATIONAL ACCOUNTING STANDARDS BOARD). 2013. Interim financial reporting IAS 34 (revised version). London: IASB.

IASC (INTERNATIONAL ACCOUNTING STANDARDS COMMITTEE). 1989. Framework for the preparation and presentation of financial statements. London: IASC. 
ICAS \& NZICA (INSTITUTE OF CHARTERED ACCOUNTANTS OF SCOTLAND \& NEW ZEALAND INSTITUTE OF CHARTERED ACCOUNTANTS). 2011. Losing the excess baggage - reducing disclosures in financial statements to what's important. London: ICAS \& NZICA.

IFAC (INTERNATIONAL FEDERATION OF ACCOUNTANTS). 2008. Financial reporting supply chain: Current perspectives and directions. New York, NY: IFAC.

IFAC (INTERNATIONAL FEDERATION OF ACCOUNTANTS). 2011. Integrating the business reporting supply chain. New York, NY: IFAC.

KUMAR, G. 2014. Determinants of readability of financial reports of US-listed Asian companies. Asian Journal of Finance and Accounting, 6(2):1-18.

LEE, T.A. \& TWEEDIE, D.P. 1975. Accounting information: An investigation of private shareholder understanding. Accounting and Business Research, Autumn:280-291.

LEE, T.A. \& TWEEDIE, D.P. 1976. The private shareholder: His sources of financial information and his understanding of reporting. Accounting and Business Research, Autumn:304-314.

LEE, T.A. \& TWEEDIE, D.P. 1977. The private shareholder and the corporate report. London. ICAEW. READER'S DIGEST. 1984. Reader's Digest great illustrated dictionary. Reader's Digest.

SAICA (SOUTH AFRICAN INSTITUTE OF CHARTERED ACCOUNTANTS). 2012. Sustainability reporting and integrated reporting. Available at: https://www.saica.co.za/TechnicalInformation/ SustainabilityandIntegratedReporting/SustainabilityReportingandIntegratedReporting/tabid/1653/language/en -ZA/Default.aspx[accessed 2013-02-14].

SEC (SECURITIES AND EXCHANGE COMMISSION). 2008. Final report of the Advisory Committee on Improvements to Financial Reporting. August. Washington, DC: SEC.

SMITH, M. \& TAFFLER, R. 1992. Readability and understandability: Different measures of the textual complexity of accounting narrative. Accounting, Auditing and Accountability Journal, 5(4):84-98.

TECHTALK. 1995. Accounting: Proposed new standard-setting process. Issue no 4. February.

WAGNER, R. \& KEMMERLING, S.M. 2010. Handling nonresponse in logistics research. Journal of Business Logistics, 31(2):357-381. 